\title{
Is thioridazine retinopathy progressive? Relationship of pigmentary changes to visual function
}

\author{
Michael F Marmor
}

\begin{abstract}
Thioridazine toxicity has been described as a 'progressive chorioretinopathy', but this designation can be misleading. During the first year after thioridazine exposure retinal pigmentation evolves from a granular to a patchy or nummular appearance. However, visual function and the electroretinogram typically improve during this period. Some cases may show chorioretinal atrophy and functional loss many years later, but there is little evidence for ongoing drug-related progression. Late atrophy may represent degeneration of cells that were injured subclinically at the time of initial drug exposure. Although thioridazine toxicity produces an evolving pigmentary disturbance, functional changes must be monitored independently of fundus appearance.
\end{abstract}

Toxicity from thioridazine has been recognised since $1960 .{ }^{1}$ Ingestion of high doses (typically exceeding $800 \mathrm{mg} /$ day) for just a few weeks may be sufficient to cause symptoms of reduced acuity and poor dark adaptation. ${ }^{1-5}$ If retinopathy is recognised at this early stage, the fundus characteristically shows coarse granular pigmentation involving the macula and sometimes mid periphery as well. However, these granular changes evolve over time into large, patchy areas of hypo- or hyperpigmentation..$^{23}$ This change in appearance has been recognised for a long time, but recent articles have attached new significance to the findings: the late appearance has been termed a 'nummular retinopathy', ${ }^{6}$ and the evolution of pigmentation called 'progressive chorioretinopathy'.?

The latter terminology implies that thioridazine toxicity progresses after the drug has been stopped, as has been reported occasionally with chloroquine toxicity. ${ }^{8-11}$ However, clinical experience with thioridazine is not altogether consistent with this description. For example, functional recovery within the first several months after stopping the drug has been noted repeatedly. ${ }^{41213}$ It is critical to make distinctions between short and long term changes, between the evolution of pigmentation and the evolution of functional loss, and between pharmacological toxicity (from retained toxin) and the time related decompensation of subclinically injured tissue.

\section{Material and methods}

We have seen seven cases of thioridazine toxicity for whom broad retinal functional parameters (electroretinogram, dark adaptation or visual fields) were measured sequentially. In four cases the examinations included the first year after toxic exposure; in six cases the examinations extended to between $5 \frac{1}{2}$ and 28 years after exposure. Table 1 summarises the drug history, fundus changes and visual function studies of these patients.
Michael F Marmor, MD

Accepted for publication 5 July 1990

Table 1 Case histories and clinical findings

\begin{tabular}{|c|c|c|c|c|c|c|c|c|c|c|}
\hline \multirow[b]{2}{*}{ Case } & \multirow[b]{2}{*}{ Sex } & \multicolumn{3}{|l|}{ Length of } & \multirow[b]{2}{*}{ Age } & \multirow[b]{2}{*}{ Fundus appearance } & \multicolumn{4}{|l|}{ Extent of } \\
\hline & & $\begin{array}{l}\text { Dose } \\
\text { (mg/day) }\end{array}$ & $\begin{array}{l}\text { Exposure (at } \\
\text { high dose) }\end{array}$ & $\begin{array}{l}\text { Time after } \\
\text { exposure }\end{array}$ & & & $\begin{array}{l}\text { Visual acuity } \\
\text { (best eye) }\end{array}$ & $\begin{array}{l}\text { Visual field } \\
\text { (perimetry) }\end{array}$ & $\begin{array}{l}\text { Dark adaptation } \\
\text { (log units threshold } \\
\text { elevation) }\end{array}$ & $\begin{array}{l}\text { Scotopic ERG } \\
\text { (\% of normal } \\
\text { min. amplitude) }\end{array}$ \\
\hline \multirow[t]{6}{*}{1} & \multirow[t]{6}{*}{$\mathbf{M}$} & \multirow[t]{6}{*}{2400} & \multirow[t]{6}{*}{5 Weeks } & 0 & \multirow{9}{*}{$\begin{array}{l}38 \\
38 \\
38 \\
39 \\
25 \\
26 \\
27 \\
31\end{array}$} & - & $20 / 70$ & - & - & - \\
\hline & & & & 3 Weeks & & Granular & $20 / 30$ & $3^{\circ}$ & - & - \\
\hline & & & & 2 Months & & - & $20 / 30$ & $4^{\circ}$ & - & - \\
\hline & & & & 3 Months & & - & $20 / 25$ & $3^{\circ}$ & - & - \\
\hline & & & & 5 Months & & Pigm. coalesced & $20 / 25$ & $22^{\circ}$ & - & - \\
\hline & & & & 13 Months & & Clumps, nummular & $20 / 25$ & $20^{\circ}$ & 2 & 5 \\
\hline \multirow[t]{3}{*}{2} & \multirow[t]{3}{*}{$\mathbf{F}$} & \multirow[t]{3}{*}{1800} & \multirow[t]{3}{*}{ 4-6 Weeks } & 2 Months & & Granular & $20 / 100$ & $20^{\circ}$ & 4 & $0^{\star}$ \\
\hline & & & & 1 Year & & Nummular & $\begin{array}{l}20 / 25 \\
20 / 30\end{array}$ & Scotomas & $0 \cdot 75$ & Normal \\
\hline & & & & $51 / 2$ Years & & Nummular & $20 / 30$ & Normal & $=$ & $\overline{\text { Normal }}$ \\
\hline \multirow[t]{4}{*}{3} & \multirow[t]{4}{*}{$\mathbf{F}$} & \multirow[t]{4}{*}{$900-1200$} & \multirow[t]{4}{*}{ 2-3 Years } & & 29 & Granular & $20 / 60$ & $3^{\circ}$ & - & $0^{\star}$ \\
\hline & & & & 7 Years & 36 & Nummular & $20 / 25$ & $10^{\circ}$ & 2 & $5-10$ \\
\hline & & & & 11 Years & 40 & Nummular & $20 / 50$ & $10^{\circ}$ & - & - \\
\hline & & & & $151 / 2$ Years & 45 & Nummular & $20 / 30$ & $5^{\circ}$ & - & - \\
\hline 4 & $\mathbf{M}$ & 1600 & 2 Months & 1 Month & 27 & Granular & $20 / 25$ & - & & Normal \\
\hline & & & & 15 Years & 41 & Mild nummular & $20 / 20$ & Scotomas & Normal & Normal \\
\hline \multirow[t]{2}{*}{5} & \multirow[t]{2}{*}{$\mathbf{M}$} & \multirow[t]{2}{*}{1200} & \multirow{4}{*}{$\begin{array}{c}>5 \text { Weeks } \\
\text { (3-4 Years } \\
\text { on drugs) } \\
1 \text { Year }\end{array}$} & $\begin{array}{l}16 \text { Years } \\
17 \text { Years }\end{array}$ & $\begin{array}{l}48 \\
49\end{array}$ & $\begin{array}{l}\text { Nummular } \\
\text { Nummular }\end{array}$ & $\begin{array}{c}20 / 25 \\
{[20 / 80]}\end{array}$ & $\begin{array}{l}\text { Scotomas } \\
{\left[5^{\circ}\right]}\end{array}$ & & $\begin{array}{l}50 \\
50\end{array}$ \\
\hline & & & & $181 / 2$ Years & 51 & Nummular & $20 / 25$ & Scotomas & 2 & 50 \\
\hline \multirow[t]{2}{*}{6} & \multirow[t]{2}{*}{$\mathbf{F}$} & \multirow[t]{2}{*}{ ? } & & 4 Years & 35 & Nummular & $20 / 20$ & - & - & - \\
\hline & & & & 20 Years & 52 & Nummular & $20 / 25$ & Scotomas & 2 & 45 \\
\hline \multirow[t]{4}{*}{7} & \multirow[t]{4}{*}{$\mathbf{M}$} & \multirow[t]{4}{*}{2400} & \multirow[t]{4}{*}{ Few months } & & 28 & - & Reduced & - & - & - \\
\hline & & & & 2 Months & 28 & - & $20 / 30$ & - & - & - \\
\hline & & & & 13 Years & $\begin{array}{l}41 \\
56\end{array}$ & Nummular & $\begin{array}{l}20 / 40 \\
20 / 25\end{array}$ & $15^{\circ}$ & $\begin{array}{l}2 \cdot 5 \\
3.5\end{array}$ & 25 \\
\hline & & & & 28 Years & 56 & Atrophic & $20 / 25$ & $2^{\circ}$ & $3 \cdot 5$ & 0 \\
\hline
\end{tabular}

^Hand held flash recordings; all others made with full field stimulus. 
Figure 1 Fundus appearance of case 3. (A) Soon after stopping thioridazine: granular retinopathy. (B) Seven years later: patchy nummular retinopathy. (C) Eleven years after thioridazine: there has been enlargement of some of the demarcated atrophic zones (arrows) that lie within larger areas of $R P E$ damage.

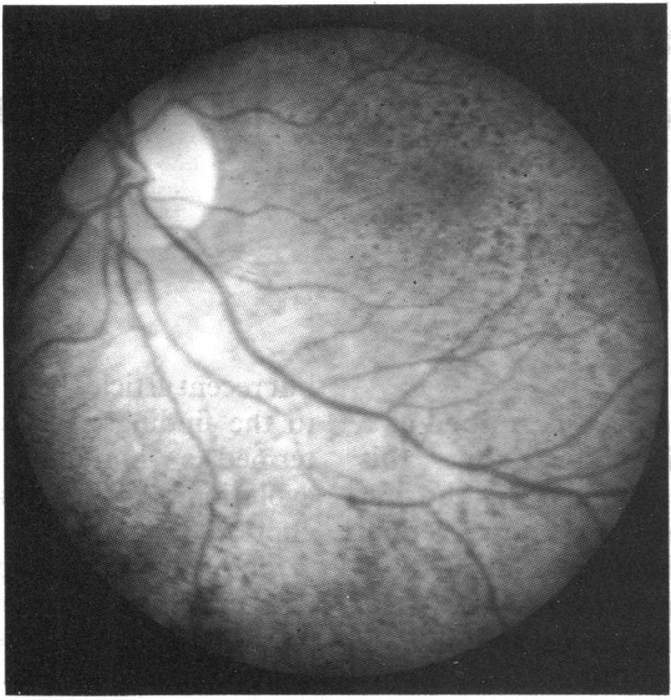

Fig $1 A$

\section{Results}

Figs 1-2 illustrate the typical progression of fundus changes. Soon after stopping thioridazine the fundus had a coarse granular appearance, most striking in the posterior pole (Fig 1A). Over the first year after cessation of the drug the pigment coalesced to produce larger pigment clumps and areas of geographic atrophy or nummular retinopathy (Fig 1B). Over the ensuing years the atrophic zones tended to enlarge very slowly, though the basic pattern of atrophy was remarkably constant over long periods of time (Fig 1C). Occasionally the nummular retinopathy progressed to diffuse end-stage atrophy (Figs $2 \mathrm{~A}, \mathrm{~B}$ ).

The functional changes associated with the early evolution (granular to nummular) and late evolution (nummular expansion) of thioridazine retinopathy are quite different. During the first year after exposure to the drug visual function typically improved despite the evolution of pigmentary changes in the fundus. Fig 3 illustrates the early functional status of cases $1-4$ by the best available sequential data - electroretinogram (ERG), dark adaptation, or visual field. Visual function was often depressed during the first few months of the toxic exposure, but showed a degree of recovery thereafter. Once the fundus appearance had stabilised (roughly one year after drug exposure), visual function either remained stable (Fig 4) or showed a rate of deterioration that was extremely slow and was measurable only

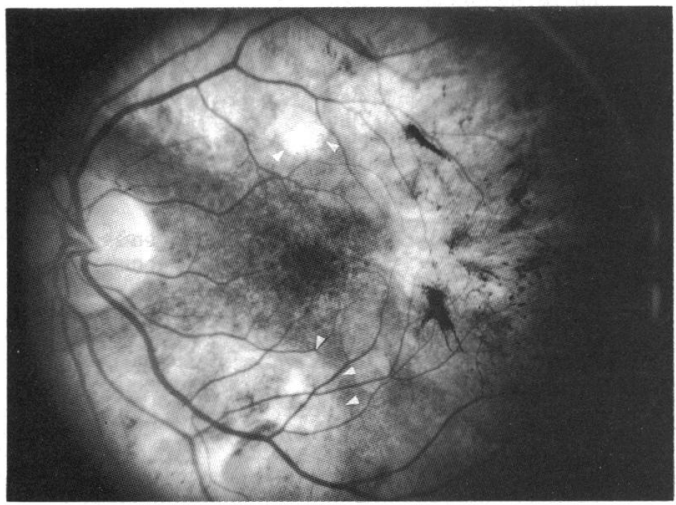

Fig $1 C$

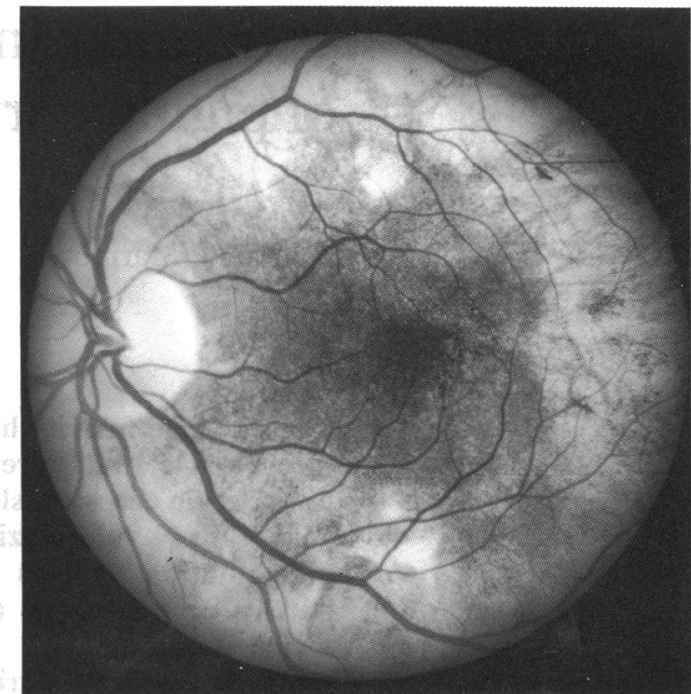

Fig $1 B$

over a period of several years. Fig 5 illustrates the late functional status of cases 2-7.

Case 5 seemed for a while to contradict this description, insofar as he complained of a rapid loss of visual acuity and visual field that began 16 years after stopping thioridazine. During the course of one year he progressed from good peripheral vision with isolated scotomas to severe tunnel vision with only a tiny $5^{\circ}$ central island, and he sought training in the use of a long cane. However, his nummular fundus lesions changed only minimally during this period, and his ERG remained stable. Confronted with the inconsistencies, he miraculously 'recovered'.

\section{Discussion}

The fundus appearance in thioridazine retinopathy evolves within the first year from the coarse granular retinopathy of acute toxicity to the patchy or nummular retinopathy of late thioridazine damage (Fig 1). However, all our cases showed significant visual improvement (or at worst, stability), during the first year after toxic levels of thioridazine were stopped, despite an increasingly atrophic fundus appearance. For example, patient 2, who initially had a very low ERG (extinguished to a hand held flash) recovered to show almost normal responses. These observations are consistent with reports of visual recovery when the drug is stopped before retinal damage is too pervasive. ${ }^{+1213}$ Thus it appears that thioridazine retinopathy does not progress functionally during the change from granular to nummular retinopathy.

Improvement during the first year after thioridazine does not rule out the possibility that the drug might continue to exert a toxic effect over the long term if drug depots remain in the tissues. Thioridazine (like other phenothiazines) is bound to melanin and may well persist in the eye for a long time. ${ }^{14}$ is Our data show that there is a risk of very slow or very late functional decompensation, and cases of late functional loss have also been reported by others, ${ }^{37}$ including two that were decumented with ERGs. ${ }^{6}{ }^{16}$ At the same time the relative stability of findings in some of my patients suggests that late functional loss may not be inevitable. 
Figure 2 Fundus appearance of case 7 . (A) Thirteen years after stopping thioridazine: patchy and diffuse RPE atrophy. $(B)$ diffuse RPE atrophy.
Twenty eight years after thioridazine: end-stage chorioretinal atrophy.

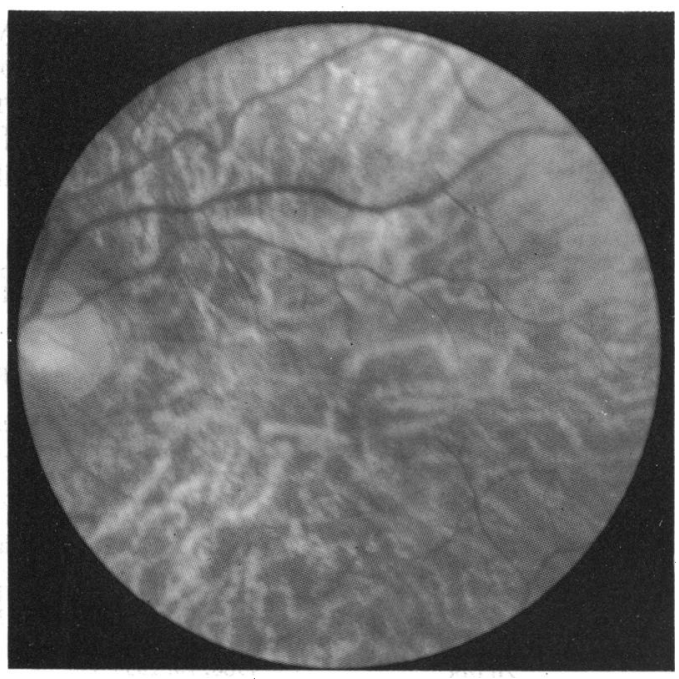

Fig $2 A$

It seems clear from our experience and published reports ${ }^{67}$ that the geographic areas of chorioretinal atrophy in thioridazine toxicity may expand very slowly. But do these late degenerative changes represent a direct pharmacological effect of thioridazine in the tissues? I find it difficult to believe that enough drug would persist to cause severe and progressive damage many years after exposure (at least 15 years for cases 3 and 4), especially when the toxic effects were diminishing or stable during earlier years.

An expansion of atrophic lesions over time can occur in diseases unrelated to drugs, such as age related maculopathy and the 'creep' of retinal pigment epithelial (RPE) atrophy ${ }^{17} 18$ that occurs months to years after macular photocoagulation. It is possible that in late thioridazine toxicity we are seeing the non-specific expansion of scars, equivalent to the late exposure of areas of subclinical drug induced RPE damage that occurred at the time of original drug usage. Thioridazine probably injures cells over larger areas of RPE than are visible initially by ophthalmoscopy or angiography. These areas of marginal injury may decompensate or degenerate years later when time and age related pathology take their toll. At least one author has asked whether similar arguments may apply to chloroquine retinopathy. ${ }^{19}$ In thioridazine cases with relatively mild initial damage (such as cases 2 and

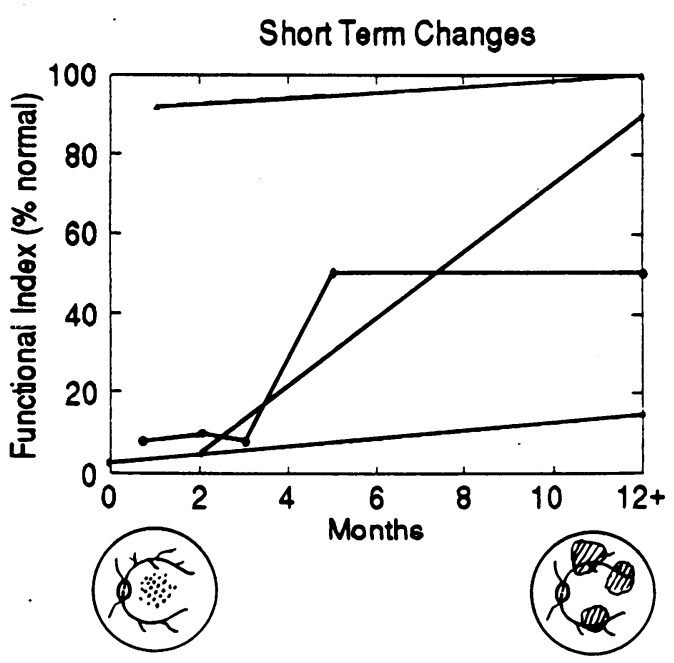

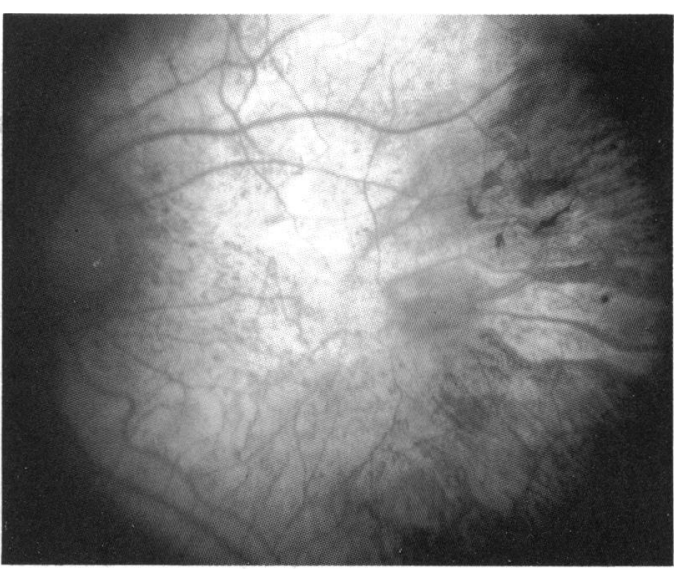

Fig 2B

4), the prognosis over the long term is probably fairly good; in patients in whom there is more widespread damage in the early years (such as cases 1,3 , and 7) the prognosis will be much more guarded, since decompensation of the compromised RPE could eventually lead to diffuse atrophy.

Until the late pigmentary and functional changes in thioridazine can be clearly shown to be a result of continued drug action I suggest that thioridazine toxicity not be referred to as a progressive chorioretinopathy. That term carries an implication of monotonic functional decline from a primary disease process. There is no question that many cases of thioridazine retinopathy show late deterioration; however, the examples in this paper show that the early fundus changes from granular to nummular retinopathy do not correlate with a 'progression' of visual loss (indeed, vision typically improves), and the late atrophic fundus changes are variable in onset and may represent a secondary decompensation. There is unquestionably a risk of late atrophic degeneration, but the cause of this retinopathy is complex, and it may not always progress.

These conclusions have important clinical implications. First, in thioridazine toxicity (and indeed retinal disease in general) pigmentary scarring is not necessarily equivalent to functional damage. Patients with thioridazine toxicity must be followed up with functional tests such as visual field and the ERG, in addition to observation of the fundus, if progression and toxicity is to be assessed accurately. Secondly, the fact that severe late loss of function does occur in occasional individuals indicates that patients with thioridazine toxicity need to be followed up indefinitely to document the stability or progression of disease. Thirdly, the hypothesis that subclinical damage may exist at the time of initial toxic exposure suggests a possible therapeutic strategy. Ischaemic damage to the retina can be minimised by treatment with dextromethorphan, ${ }^{20}$ which blocks the secondary death of marginally injured cells by the release of excitatory amino acids. If agents can eventually be found that reduce the amount of secondary RPE decompensation after thioridazine exposure, the long term visual risks would be greatly reduced.

Case 5 reminds us of an additional caveat: functional tests may be influenced by nonorganic factors. Many patients using thioridazine have psychiatric disease, and their subjective 
TIME AFTER THIORIDAZINE

1 year

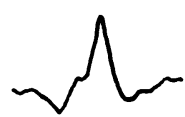

5.5 years

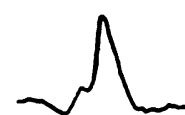

maximat

(scotopic)

\section{HAND-HELD FLASH ERG}

\section{FULL-FIELD ERG}

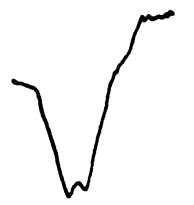

Figure 4 Electroretinograms from case 2, recorded at intervals after stopping thioridazine.

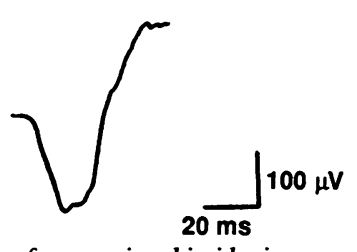

\section{Long Term Changes}

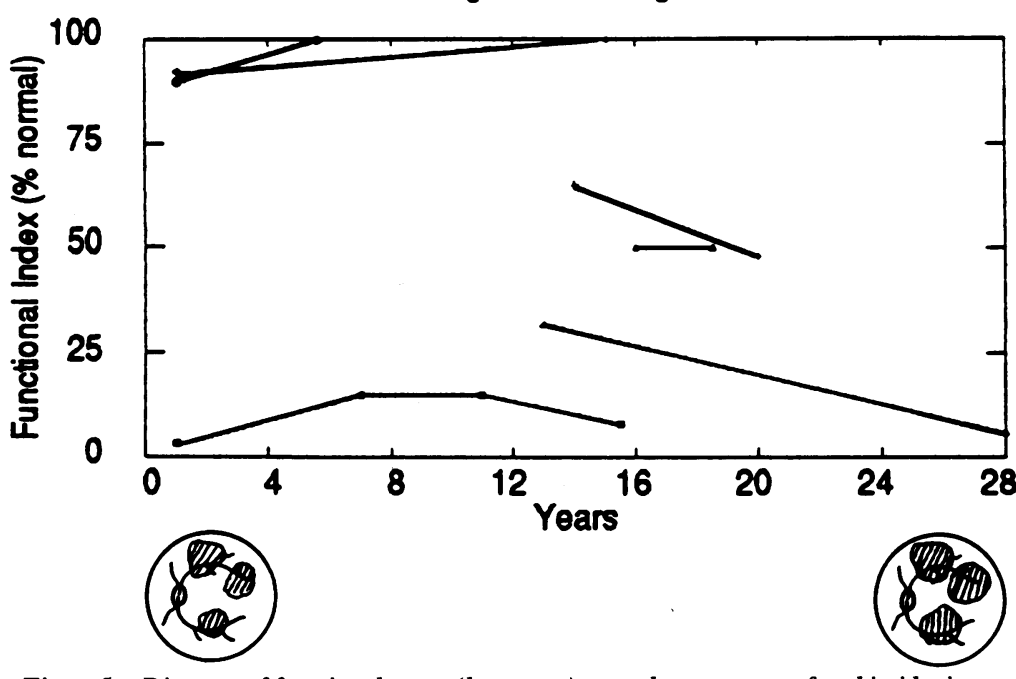

Figure 5 Diagram of functional status (long-term) more than one year after thioridazine exposure for cases 2-7. Functional index is defined as in Fig 3.

responses may vary with mental status and/or secondary gain. If objective measures such as fundus photography and ERG had not been performed repeatedly on case 5 , a very convincing story for progressive retinopathy might have been made. Psychophysical tests may be sufficient for routine follow-up when there is no progression of visual symptoms, but it is important to have a baseline of objective data at the time of initial diagnosis to allow for later comparisons that may be needed.

This work was supported in part by NIH-NEI Research Grant EY01678, and an unrestricted grant from Research to Prevent Blindness, Inc.

1 Weekley RD, Potts AM, Reboton J, May RH. Pigmentary retinopathy in patients receiving high doses of a new phenothiazine. Arch Ophthalmol 1960; 64: 95-106.

2 Zinn K, Marmor MF. Clinical toxicology of the retinal pigment epithelium. In: Zinn $\mathrm{K}$, Marmor MF, eds. The retinal pigment epithelium. Cambridge: Harvard University Press, 1979: 381-94.

3 Davidorf FH. Thioridazine pigmentary retinopathy. Arch Ophthalmol 1973; 90: 251-5.

4 Cohen J, Wells J, Borda R. Thioridazine (Mellaril) ocular toxicity. Doc Ophthalmol Proc Ser 1978; 15: 91-4.

toxicity. Doc Ophthalmol Proc Ser 1978; 15: $91-4$. 1966; 70: 1054-7.

6 Kozy D, Doft BH, Lipkowitz J. Nummular thioridazine retinopathy. Retina 1984; 4: 253-6.

7 Meredith TA, Aaberg TM, Willerson WD. Progressive chorioretinopathy after receiving thioridazine. Arch Ophthalmol 1978; 96: 1172-6.

8 Ogawa S, Kurumatani N, Schibaike N, Yamazoe S. Progression of retinopathy long after cessation of chloroquine therapy. Lancet 1979; i: 1408

9 Schmoger E, Muller W, Haase E. Follow-up in a case of retinopathy more than 10 years after stopping chloroquine herapy. Doc Ophthalmol Proc Ser 1978; 15: 101-5.

10 Sassani JW, Brucker AJ, Cobbs W, Campbell C. Progressive , Cobbs W, Campbell C. Progressive chloroquine retinopathy. Ann Ophthalmol 1983; 15: 19-22.

11 Ehrenfeld M, Nesher R, Merin S. Delayed-onset chloroquin retinopathy. Brf Ophthalmol 1986; 70: 281-3.

12 Leinfelder PJ, Burian HM. Mellaril intoxication of retina with full restitution of function. Invest Ophthalmol Vis Sci 1964; 3: 466 .

13 Connel MM, Poley BJ, McFarlane JR. Chorioretinopathy associated with thioridazine therapy. Arch Ophthalmol 1964; 71: 816-21.

14 Potts AM. The concentration of phenothiazines in the eye of experimental animals. Invest Ophthalmol Vis Sci 1962; 1: 522-30.

15 Cerletti A, Meier-Ruge W. Toxicological studies on phenothiazine induced retinopathy. In: Baker SB de C, Boissier JR, Koll W, eds. Proceedings of the European Society for Study of Drug Toxicity. Amsterdam: Excerpta Medica, 1968: 9: of Drug

16 Fishman G. Thioridazine hydrochloride (Mellaril) toxic pigmentary chorioretinopathy. In: Smith JL, ed. Neuro-

17 Shah SS, Schachat AP, Murphy RP, Fine SL. The evolution of argon laser photocoagulation scars in patients with the ocular histoplasmosis syndrome. Arch Ophthalmol 1988; 106: 1533-6.

18 Morgan CM, Schatz H. Atrophic creep of the retinal pigmen epithelium after focal macular photocoagulation. Ophthal mology 1989; 96: 96-103.

19 Brinkley JR, Dubois EL, Ryan SJ. Long-term course of chloroquine retinopathy after cessation of medication. $A m \mathcal{F}$ Ophthalmol 1979; 88: 1-11.

20 Yoon YH, Marmor MF. Dextromethorphan enhances ERG recovery after retinal ischemia. Arch Ophthalmol 1989; 107: 409-11. 